\title{
BMJ Open Cross-sectional analysis of ethnic differences in fall prevalence in urban dwellers aged 55 years and over in the Malaysian Elders Longitudinal Research study
}

\author{
Deepa Alex, ${ }^{1}$ Hui Min Khor, ${ }^{1,2}$ Ai Vyrn Chin, ${ }^{1,2}$ Noran Naqiah Hairi, ${ }^{3}$ \\ Sajaratulnisah Othman, ${ }^{4}$ Selina Phaik Kin Khoo, ${ }^{5}$ \\ Shahrul Bahyah Kamaruzzaman,, ${ }^{1,2}$ Maw Pin $\operatorname{Tan}^{1,2}$
}

To cite: Alex D, Khor HM, Chin AV, et al. Cross-sectional analysis of ethnic differences in fall prevalence in urban dwellers aged 55 years and over in the Malaysian Elders Longitudinal Research study. BMJ Open 2018;8:e019579. doi:10.1136/ bmjopen-2017-019579

- Prepublication history for this paper is available online. To view these files, please visit the journal online (http://dx.doi. org/10.1136/bmjopen-2017019579).

Received 11 September 2017 Revised 15 June 2018 Accepted 22 June 2018

Check for updates

(C) Author(s) (or their employer(s)) 2018. Re-use permitted under CC BY-NC. No commercial re-use. See rights and permissions. Published by BMJ.

For numbered affiliations see end of article.

Correspondence to

Dr Maw Pin Tan;

mptan@ummc.edu.my

\section{ABSTRACT}

Objectives Falls represent major health issues within the older population. In low/middle-income Asian countries, falls in older adults remain an area which has yet to be studied in detail. Using data from the Malaysian Elders Longitudinal Research (MELoR), we have estimated the prevalence of falls among older persons in an urban population, and performed ethnic comparisons in the prevalence of falls.

Design Cross-sectional analysis was carried out using the first wave data from MELoR which is a longitudinal study. Setting Urban community dwellers in a middle-income South East Asian country.

Participants 1565 participants aged $\geq 55$ years were selected by simple random sampling from the electoral rolls of three parliamentary constituencies.

Outcome measures Consenting participants from the MELoR study were asked the question 'Have you fallen down in the past 12 months?' during their computerassisted home-based interviews. Logistic regression analyses were conducted to compare the prevalence of falls among various ethnic groups.

Results The overall estimated prevalence of falls for individuals aged 55 years and over adjusted to the population of Kuala Lumpur was $18.9 \%$. The estimated prevalence of falls for the three ethnic populations of Malays, Chinese and Indian aged 55 years and over was $16.2 \%, 19.4 \%$ and $23.8 \%$, respectively. Following adjustment for ethnic discrepancies in age, gender, marital status and education attainment, the Indian ethnicity remained an independent predictor of falls in our population (relative risk $=1.45,95 \% \mathrm{Cl} 1.08$ to 1.85 ). Conclusion The prevalence of falls in this study is comparable to other previous Asian studies, but appears lower than Western studies. The predisposition of the Indian ethnic group to falls has not been previously reported. Further studies may be needed to elucidate the causes for the ethnic differences in fall prevalence.

\section{INTRODUCTION}

Falls are common among older people and are a major cause of morbidity, mortality and
Strengths and limitations of this study

- This is the first study to look at prevalence of falls in urban community-dwelling older people in Malaysia.

- Ethnic differences in fall prevalence have not been previously reported in Malaysia.

- Our study was conducted in an urban area which may not be representative of the national population.

- The reasons for differences in fall prevalence among different ethnic groups are a topic for future studies.

- We have examined the prevalence of falls in the preceding 12 months by retrospective recall, which is now the commonly employed method to measure falls. However, validity is difficult to determine.

reduced quality of life. The consequences of a fall include traumatic brain injuries, limb fractures, loss of confidence and institutionalisation, which represent major public health issues. ${ }^{12} \mathrm{~A} 10$-year prospective study of individuals presenting with falls to the emergency department revealed that falls are associated with increased dependency and a high mortality rate. ${ }^{3}$ The financial burden associated with falls directly related to healthcare services and indirectly as loss of social productivity is high. ${ }^{4}$ The cost of falls will increase with global population ageing unless effective strategies are developed to reduce their burden.

The prevalence of falls has been reported as $19 \%-26 \%$ in individuals aged $\geq 65$ years and over $^{56}$ and $27 \%-32 \%$ in those aged 70 years and over. ${ }^{78}$ It remains unclear whether fall prevalence differs according to geographical regions as many Asian studies have reported a lower prevalence of falls compared with North American, European and Australian studies. ${ }^{4910}$ The differences 
in prevalence measured in different studies may be due to differences in study design and sample populations. A handful of studies have reported ethnic and racial differences in fall prevalence. ${ }^{11} 12$ Older Asians have been reported to have lower fall rates when compared with whites residing in the same region. ${ }^{13} 14$ These ethnic differences may be due to varying reasons which include cultural, behavioural or health-related factors. A study conducted among older US women reported lower fall prevalence but more self-reported mobility limitations among Asian women, suggesting that they may be limiting their activities based on their self-perceived limitations, hence leading to a lower fall risk. ${ }^{15}$ Cultural factors such as differences in levels of concerns about the individual's health, engaging in regular physical activities such as yoga or Tai-Chi may also play a role in affecting fall prevalence. ${ }^{16}$ The determination of whether ethnic differences in fall prevalence exist in various geographical regions will help identify whether genetic and cultural factors may also contribute to fall risk. In addition, as the vast majority of published studies on fall prevention measures have been conducted in Caucasian populations, the degree of which existing published evidence may be translated to other ethnic groups and geographical locations will also be determined by potential ethnic differences in falls.

Malaysia is a multiethnic nation with the three major Asian ethnic groups: Malays $(67.4 \%)$, Chinese $(24.6 \%)$ and Indians $(7.3 \%) .{ }^{17}$ The sizeable population of each ethnic group, residing within the same geographical area, provides us with the opportunity to identify potential ethnic differences in fall prevalence. We have, therefore, determined the prevalence of falls for the overall population as well as according to ethnic groups in an urban area in Malaysia.

\section{METHODS}

\section{Study population}

This cross-sectional study included participants from the Malaysian Elders Longitudinal Research (MELoR) study. The MELoR study is a longitudinal cohort study based in Kuala Lumpur and its surrounding suburbs (Klang Valley). Individuals aged 55 years and above were selected through simple random sampling from the electoral rolls of the parliamentary constituencies of Petaling Jaya North, Petaling Jaya South and Lembah Pantai, stratified by the three ethnic groups and by 5 -year age groups. A total of 8769 invitations were sent out to the main ethnic groups and volunteers were invited through focused community groups. Up to 5815 participants with contactable addresses were identified from the above-mentioned group. Individuals who were bedbound, unable to be transported to the research centre for assessment and unable to communicate due to advanced dementia or severe speech impediments were excluded from the study. ${ }^{18}$ Complete data on all variables of interest for the present study were available in 1565 participants. This study was approved by the University of Malaya Medical Centre Medical Ethics Committee and complied with the Helsinki Declaration of 1975, revised in 1983. Written informed consent was obtained from all study participants prior to their inclusion. The inclusion criteria were age 55 years and above, were able to provide informed consent and belonging to one of the three major ethnic groups of Malay, Chinese or Indian. The voluntary retirement age for Malaysia at the time of study commencement was 55 years, and so using a cut-off of 55 years enabled the analysis of health issues of individuals as they approached retirement.

\section{Data collection}

Participants were contacted and visited at their own homes initially to recruit them into the study. A structured interview using a computer-aided questionnaire was completed during this encounter. Participants were then requested to attend the hospital for a detailed health check. Information on basic demographics (including age, sex and ethnicity) was collected during the initial home visit. At this home visit, participants were asked the question 'Have you fallen in the past 12 months?' with answer categories: 1 'No' and 2 'Yes'. A fall was defined as 'unintentionally coming to rest on the ground, floor, or lower level'. ${ }^{19}$

\section{Statistical analysis}

Data analyses were conducted using SPSS V.23 (IBM). As age was a continuous variable, the ethnic differences in age were evaluated using analysis of variance, while ethnic differences were determined using the $\mathrm{X}^{2}$ test for the remaining variables in terms of baseline characteristics which were categorical variables. The differences in prevalence of falls with age were compared with the independent t-test later. We also categorised the participants into 5-year age bands: 55-59, 60-64, 65-69, 70-74 and $\geq 75$ years. The crude prevalence of falls was estimated by age groups and ethnicity. As the sample was stratified to allow for equal representation of the three ethnic groups and the different age groups in the cohort study, weighted data analysis was necessary in order to estimate prevalence for the local population. Sample weights were calculated by ethnicity and 5 -year age groups using population statistics published by the Department of Statistics, Malaysia, obtained from the 2010 population census. ${ }^{17}$ Modified binary logistic regression was carried out to compare prevalence of falls among the ethnic groups using the Malay ethnicity as the reference group to estimate relative risk. ${ }^{20}$ Modified multiple logistic regression was then performed with the factors age, gender, partner status and education to eliminate potential confounding effects. Interactions between age, education and ethnicity were assessed using product terms. P values of less than 0.05 were considered statistically significant. 
Table 1 Basic characteristics according to ethnicity

\begin{tabular}{|c|c|c|c|c|c|}
\hline & Total $(n=1565)$ & Malay $(n=519)$ & Chinese $(n=544)$ & Indian $(n=502)$ & P values* \\
\hline Age (years), mean $\pm S D$ & $68.9 \pm 7.5$ & $67.8 \pm 7.1$ & $69.4 \pm 7.4$ & $69.5 \pm 7.9$ & $<0.001$ \\
\hline Age categories (years), $\mathrm{n}(\%)$ & & & & & 0.015 \\
\hline $55-59$ & $189(12.1)$ & $72(13.9)$ & $52(9.6)$ & $65(12.9)$ & \\
\hline $60-64$ & $325(20.8)$ & $126(24.3)$ & $111(20.4)$ & $88(17.5)$ & \\
\hline $65-69$ & $361(23.1)$ & $117(22.5)$ & $133(24.4)$ & $111(22.1)$ & \\
\hline $70-74$ & $364(23.3)$ & $118(22.7)$ & $131(24.1)$ & $115(22.9)$ & \\
\hline$\geq 75$ & $326(20.8)$ & $86(16.6)$ & $117(21.5)$ & $123(24.5)$ & \\
\hline Female gender, n (\%) & $892(57.0)$ & $282(54.3)$ & $331(60.8)$ & $279(55.6)$ & 0.074 \\
\hline Single/widowed, n (\%) & $414(26.5)$ & $127(24.5)$ & $121(22.2)$ & $166(33.2)$ & $<0.001$ \\
\hline Secondary/tertiary education, $\mathrm{n}(\%)$ & $1133(72.4)$ & $298(57.6)$ & $447(82.2)$ & $388(77.3)$ & $<0.001$ \\
\hline Smoker, n (\%) & 309 (19.7) & $133(26.1)$ & $90(16.9)$ & $86(17.6)$ & $<0.001$ \\
\hline
\end{tabular}

${ }^{*} \mathrm{X}^{2}$ test for categorical variables and analysis of variance for age.

\section{Patient and public involvement statement}

As this was a population-based cohort study, non-governmental organisations, senior citizens' groups and charitable organisations were consulted in a consultation forum followed by focus groups to identify key issues they felt they would like addressed. The MELoR questionnaire was scrutinised by older persons from local senior citizens' groups and their feedback given due consideration in refining the questionnaire. Our recruitment process involved engaging local community leaders who then assisted us with first organising local publicity events which included health talks, free health screening or exercise sessions. Selected participants were then accessed by identifying these individuals or their neighbours at these events, and enlisting the help of local residents in door-to-door recruitment. Participants were provided with individual feedback during their health check by a medical specialist and this was followed by a written report of their screening results. Preliminary aggregated results have been presented to local residents through numerous local follow-up publicity events, and further individual feedback is planned during subsequent waves.

\section{RESULTS}

Data on falls were available for 1565 individuals: 519 were ethnic Malays, 544 ethnic Chinese and 502 ethnic Indians. Table 1 shows the sociodemographic characteristics of the sample population according to ethnicity. There were significant differences in age, marital status, education and smoking status according to ethnicity.

\section{Prevalence of falls}

The crude prevalence for the overall population aged 55 years and over was $22.8 \%$, and for those aged 65 years and over was $24.5 \%$. The crude prevalence of falls among the ethnic Malays aged 55 years and over was $18.9 \%$ compared with the ethnic Chinese at $22.4 \%$ and the ethnic Indians at $27.3 \%$. The crude prevalence of falls according to age groups and ethnic groups is shown in table 2. The prevalence of falls increased significantly with age (mean age $\pm \mathrm{SD}$ of fallers vs non-fallers $=70.4 \pm 8.1$ vs $68.4 \pm 7.2 ; \mathrm{p}<0.001)$. Weighted prevalence was then estimated according to the population composition of Kuala Lumpur. The estimated true prevalence of falls for all ethnic Malays aged 55 years and over was $16.2 \%$, Chinese $19.4 \%$ and Indians $23.8 \%$. The prevalence of falls increased with age for the overall population and all three ethnic groups. The overall prevalence of falls weighted for the population of Kuala Lumpur aged 55 years and over was $18.9 \%$. The weighted prevalence of falls for individuals aged 65 years and over was $23.5 \%$.

\section{Ethnic differences in fall prevalence}

Table 3 shows the relative risk for falls for the ethnic Chinese and ethnic Indians compared with the ethnic Malays unadjusted, and adjusted for age, gender, marital status and education. Compared with the ethnic Malays, the ethnic Indians were significantly more likely to fall in unadjusted analysis $(\mathrm{p}=0.012)$. After adjustment for age and gender and further adjustment for marital status and

Table 2 Crude prevalence of falls according to age group and ethnicity

\begin{tabular}{lcrrl}
\hline \multirow{2}{*}{$\begin{array}{l}\text { Age group } \\
\text { (years) }\end{array}$} & \multicolumn{1}{l}{ Falls, $\mathbf{n}(\%)^{*}$} & & & \\
\cline { 2 - 5 } & Overall & \multicolumn{1}{l}{ Malay } & Chinese & Indian \\
\hline $55-59$ & $30(15.8)$ & $9(12.5)$ & $8(15.4)$ & $13(20.0)$ \\
$60-64$ & $69(21.2)$ & $23(18.2)$ & $24(21.6)$ & $22(25.0)$ \\
$65-69$ & $76(21.0)$ & $18(15.4)$ & $31(23.3)$ & $27(24.3)$ \\
$70-74$ & $77(21.1)$ & $28(23.7)$ & $21(16.0)$ & $28(24.3)$ \\
$75+$ & $105(32.2)$ & $20(23.3)$ & $38(32.5)$ & $47(38.2)$ \\
\hline
\end{tabular}

${ }^{*}$ Crude prevalence is presented as percentages in parenthesis. 
Table 3 Univariate and multiple logistic regression for ethnic differences

\begin{tabular}{|c|c|c|c|}
\hline & \multicolumn{3}{|l|}{ Falls } \\
\hline & $\begin{array}{l}\text { Relative } \\
\text { risk }\end{array}$ & $95 \% \mathrm{Cl}$ & $P$ values \\
\hline \multicolumn{4}{|l|}{ Model 1} \\
\hline \multicolumn{4}{|l|}{ Ethnicity } \\
\hline \multicolumn{4}{|l|}{ Malay (reference) } \\
\hline Chinese & 1.19 & 0.89 to 1.59 & 0.230 \\
\hline Indian & 1.44 & 1.08 to 1.92 & 0.012 \\
\hline \multicolumn{4}{|l|}{ Model 2} \\
\hline \multicolumn{4}{|l|}{ Ethnicity } \\
\hline \multicolumn{4}{|l|}{ Malay (reference) } \\
\hline Chinese & 1.12 & 0.83 to 1.50 & 0.451 \\
\hline Indian & 1.38 & 1.03 to 1.84 & 0.030 \\
\hline Age $^{*}$ & 1.03 & 1.01 to 1.04 & 0.001 \\
\hline Female gender & 1.36 & 1.07 to 1.74 & 0.012 \\
\hline \multicolumn{4}{|l|}{ Model 3} \\
\hline \multicolumn{4}{|l|}{ Ethnicity } \\
\hline \multicolumn{4}{|l|}{ Malay (reference) } \\
\hline Chinese & 1.20 & 0.88 to 1.63 & 0.239 \\
\hline Indian & 1.45 & 1.08 to 1.95 & 0.014 \\
\hline Age* $^{*}$ & 1.03 & 1.01 to 1.04 & 0.001 \\
\hline Female gender & 1.31 & 1.01 to 1.70 & 0.038 \\
\hline Single/widowed & 1.03 & 0.79 to 1.36 & 0.818 \\
\hline $\begin{array}{l}\text { Secondary/tertiary } \\
\text { education }\end{array}$ & 1.28 & 0.99 to 1.66 & 0.061 \\
\hline
\end{tabular}

Model 1: unadjusted.

Model 2: adjusted for age and gender.

Model 3: adjusted for age, gender, marital status and education level.

${ }^{*}$ Per year increase.

educational level, the ethnic Indians remained statistically more likely to report at least one fall in the preceding year compared with the ethnic Malays. Inclusion of the product terms for ethnicity and level of education as well as ethnicity and age found no significant interaction effect between education and age with ethnicity.

\section{DISCUSSION}

The population adjusted prevalence of falls among adults aged 55 years and over residing in Kuala Lumpur was $18.9 \%$, and for those aged 65 years and over was $23.5 \%$. There was an increase in fall prevalence with older age. Among the ethnic groups, the Indian ethnicity was associated with higher prevalence of falls when compared with the ethnic Malays. Our study was the first to report the prevalence of falls in the urban population in Malaysia and the first to demonstrate increased risk of falls in ethnic Indians in an Asian population.
Previous studies showed that the proportion of falls in ages 65 years and above varied between $18 \%$ and $28 \%$ per year. $^{721}$ The fall prevalence reported in our urban population was comparatively lower than that reported by previous studies performed in the UK and USA. ${ }^{4}$ The prevalence of falls has been observed to vary widely in different parts of the world. Studies from the Caribbean and Latin Americans also reported higher fall rates from $21.6 \%$ to $34 \% .{ }^{22}$ Fall prevalence in the Australian population was reported as $30 \% .^{23} \mathrm{~A}$ recent report from the Irish Longitudinal Study of Ageing involving individuals aged 50 years and over reported a prevalence of $19.2 \% .^{24} \mathrm{~A}$ systematic review of 21 studies from Asian countries on falls found that the fall prevalence varied between $14.7 \%$ and $34 \%$ in older Chinese population, ${ }^{9}$ which was comparable to our Chinese population.

Age is a well-established risk factor for falls. ${ }^{21}$ In our study, with each year's increase in age, the odds of falls increases by $4 \%$, and with the overall prevalence of falls increasing to $32 \%$ in the overall population aged 75 years and above. A study from Hong Kong showed that advanced age was associated with greater prevalence and incidence of falls. ${ }^{25}$ The prevalence of falls was observed to increase from $24 \%$ to $37 \%$ for those above the age of 80 years when compared with those in their 60 s. ${ }^{7}$ Within our cohort, fall rates were similar in the 60-74years age group, and only increased in the over $75 \mathrm{~s}$, overall. However, the increase in fall rate appears to occur earlier among the ethnic Malays, at $70-74$ years age bracket, compared with over 75 years for the ethnic Chinese and Indians.

Ethnic differences have been studied in the American population where it was reported that African Americans were less likely to fall than whites, but these differences were influenced by potential confounders. ${ }^{26}$ Similar findings were reported in another study from the USA, among older community-dwelling Caucasian and Afro-American women. ${ }^{27} \mathrm{~A}$ study from Singapore showed that ethnic Malays had a significantly higher likelihood of falls compared with the Singaporean Chinese. ${ }^{28}$ In contrast, our study found no significant difference in fall prevalence between the ethnic Chinese and Malays. The proportion of ethnic Malays, however, only comprised $8 \%$ of the overall population in the previous study. ${ }^{28}$ The differences between Singaporean Malays and Malaysian Malays are of interest, and may be explained by differences in occupation, physical activity or social structure. This study was the first to report increased risk of falls in ethnic Indians in comparison to the ethnic Malays. Our study was, however, not able to establish any underlying rationale for the ethnic differences, which would be a subject for future research. While age, gender and educational level were significantly associated with increased fall risk, these factors did not influence the relationship between falls and ethnicity in our study. 
The presence of falls in the preceding year was determined by retrospective recall. Previous reports have suggested that retrospective fall recall may not be fully accurate as older adults have a tendency to forget they had fallen, depending on various factors such as recall interval, injury-associated fall and their cognitive status. ${ }^{29}$ A systematic review of methods of measuring falls in randomised controlled fall prevention trials found that there was a substantial lack of standardisation in the use of terminology and documentation methods of falls. The study looked at 90 publications out of which $27 \%$ used retrospective reporting methods such as telephone interview, faceto-face interview and postal questionnaires while $42 \%$ used prospective reporting methods such as calendars and diaries, of which the latter were recommended. ${ }^{30}$ However, the ability to conduct prospective recording using fall diaries in population-based studies would be technically challenging with many of our older persons having problems with documenting their falls properly. Another study which examined reliability of patients' own reports of falls found that the question 'Did you fall' had a sensitivity of $91.5 \%$ and a specificity and positive predictive value of $100 \%$ as a tool in the accident and emergency setting. ${ }^{31}$ This study was carried out in an urban area, hence it may not be representative of the rural or semiurban regions of Malaysia. Further studies will be needed to identify the aetiology underlying ethnic differences in fall prevalence, as well as determine whether these differences still exist in prospective studies.

\section{CONCLUSION}

The estimated prevalence of falls among individuals aged 55 years and older in an urban area in Malaysia was $18.9 \%$. Among the different ethnic groups in the study, the prevalence of falls was significantly higher among ethnic Indians compared with the ethnic Malays. Future studies should now seek to identify factors determining the ethnic differences in fall risk.

\author{
Author affiliations \\ ${ }^{1}$ Division of Geriatric Medicine, Department of Medicine, University of Malaya \\ Medical Centre, Kuala Lumpur, Malaysia \\ ${ }^{2}$ Ageing and Age-Associated Disorders Research Group, Faculty of Medicine, \\ University of Malaya, Kuala Lumpur, Malaysia \\ ${ }^{3}$ Julius Centre, Department of Social and Preventive Medicine, Faculty of Medicine, \\ University of Malaya, Kuala Lumpur, Malaysia \\ ${ }^{4}$ Department of Primary Care Medicine, Faculty of Medicine, University of Malaya, \\ Kuala Lumpur, Malaysia \\ ${ }^{5}$ Sports Centre, University of Malaya, Kuala Lumpur, Malaysia
}

Acknowledgements We are grateful to representatives from the non-governmental organisations, senior citizens' groups and older persons' charities who assisted with our focus group discussion. We thank all residents and resident groups of the parliamentary constituencies of Petaling Jaya North, Petaling Jaya South and Lembah Pantai who assisted us with publicity events and recruitment. Special thanks to members of the Damansara Jaya Senior Citizens' Association and SECITA who assisted with improving our questionnaires.
Contributors AVC, NNH, SO, SPKK, SBK and MPT conceived the study, contributed to study design, obtained the funding for the study and were responsible to the conduct of the study. HMK was involved in data collection. DA, HMK and MPT contributed to data analysis. All authors contributed towards the writing of the manuscript and approved the final submitted version.

Funding This study was funded by a Ministry of Higher Education High Impact Research Grant (UM.C/625/1/HIR/MOHE/ASH/02). The authors in this study are also recipients of a University of Malaya Grand Challenge Fund (GC002-14HTM).

Competing interests None declared.

Patient consent Obtained.

Ethics approval University of Malaya Medical Centre Research Ethics Committee.

Provenance and peer review Not commissioned; externally peer reviewed.

Data sharing statement Due to concerns about loss of fidelity of personally identifiable data, the MELOR data set is currently not available publicly. However, parts of the data set will be released anonymised through written requests submitted to the corresponding author.

Open access This is an open access article distributed in accordance with the Creative Commons Attribution Non Commercial (CC BY-NC 4.0) license, which permits others to distribute, remix, adapt, build upon this work non-commercially, and license their derivative works on different terms, provided the original work is properly cited, appropriate credit is given, any changes made indicated, and the use is non-commercial. See: http://creativecommons.org/licenses/by-nc/4.0/.

\section{REFERENCES}

1. Stevens JA, Corso PS, Finkelstein EA, et al. The costs of fatal and non-fatal falls among older adults. Inj Prev 2006;12:290-5.

2. Hartholt KA, van Beeck EF, Polinder S, et al. Societal consequences of falls in the older population: injuries, healthcare costs, and longterm reduced quality of life. J Trauma 2011;71:748-53.

3. Tan MP, Kamaruzzaman SB, Zakaria MI, et al. Ten-year mortality in older patients attending the emergency department after a fall. Geriatr Gerontol Int 2016;16:111-7.

4. Ageing WHO, Unit LC. WHO global report on falls prevention in older age: World Health Organization, 2008.

5. Bekibele CO, Gureje O. Fall incidence in a population of elderly persons in Nigeria. Gerontology 2010;56:278-83.

6. Milat AJ, Watson WL, Monger C, et al. Prevalence, circumstances and consequences of falls among community-dwelling older people: results of the 2009 NSW Falls Prevention Baseline Survey. N S W Public Health Bull 2011;22:43-8.

7. Siqueira FV, Facchini LA, Silveira DS, et al. Prevalence of falls in elderly in Brazil: a countrywide analysis. Cad Saude Publica 2011;27:1819-26.

8. Varas-Fabra F, Castro Martín E, Pérula de Torres LA, et al. [Falls in the elderly in the community: prevalence, consequences, and associated factors]. Aten Primaria 2006;38:450-5.

9. Kwan MM, Close JC, Wong AK, et al. Falls incidence, risk factors, and consequences in Chinese older people: a systematic review. $J$ Am Geriatr Soc 2011;59:536-43.

10. Lim J-Y, Park W-B, Oh M-K, et al. Falls in a proportional region population in Korean elderly: incidence, consequences, and risk Factors. J Korean Geriatr Soc 2010;14:8-17.

11. Stanaway FF, Cumming RG, Naganathan V, et al. Ethnicity and falls in older men: low rate of falls in Italian-born men in Australia. Age Ageing 2011;40:595-601.

12. Han BH, Ferris R, Blaum C. Exploring ethnic and racial differences in falls among older adults. J Community Health 2014;39:1241-7.

13. Karlsson MK, Ribom EL, Nilsson JÅ, et al. International and ethnic variability of falls in older men. Scand $J$ Public Health 2014;42:194-200.

14. Bergen G, Stevens MR, Burns ER. Falls and fall injuries among adults aged $\geq 65$ years - United States, 2014. MMWR Morb Mortal Wkly Rep 2016;65:993-8.

15. Geng Y, Lo JC, Brickner L, et al. Racial-ethnic differences in fall prevalence among older women: a cross-sectional survey study. BMC Geriatr 2017;17:65.

16. Saravanakumar P, Higgins IJ, van der Riet PJ, et al. The influence of tai chi and yoga on balance and falls in a residential care setting: $A$ randomised controlled trial. Contemp Nurse 2014;48:76-87.

17. Department of Statistics M. Population Distribution and Basic Demographic Characteristic Report 2010. 2011. https://www.dosm. gov.my/v1/index.php?r=column/cthemeByCat\&cat=117\&bul_id= 
MDMxdHZjWTk1SjFzTzNkRXYzcVZjdz09\&menu_id=LOpheU43 NWJwRWVSZkIWdzQ4TIhUUT09 (accessed 12 Jul 2017).

18. Lim LM, McStea M, Chung WW, et al. Prevalence, risk factors and health outcomes associated with polypharmacy among urban community-dwelling older adults in multi-ethnic Malaysia. PLoS One 2017;12:e0173466.

19. Buchner DM, Hornbrook MC, Kutner NG, et al. Development of the common data base for the FICSIT trials. J Am Geriatr Soc 1993;41:297-308.

20. Diaz-Quijano FA. A simple method for estimating relative risk using logistic regression. BMC Med Res Methodol 2012;12:14.

21. Yu PL, Qin ZH, Shi J, et al. Prevalence and related factors of falls among the elderly in an urban community of Beijing. Biomed Environ Sci 2009;22:179-87.

22. Reyes-Ortiz CA, Al Snih S, Markides KS. Falls among elderly persons in Latin America and the Caribbean and among elderly MexicanAmericans. Rev Panam Salud Publica 2005;17(5-6):362-9.

23. Gill T, Taylor AW, Pengelly A. A population-based survey of factors relating to the prevalence of falls in older people. Gerontology 2005;51:340-5

24. Bhangu J, King-Kallimanis BL, Donoghue OA, et al. Falls, nonaccidental falls and syncope in community-dwelling adults aged 50 years and older: Implications for cardiovascular assessment. PLoS One 2017;12:e0180997.

25. Chu LW, Chi I, Chiu AY. Incidence and predictors of falls in the Chinese elderly. Ann Acad Med Singapore 2005;34:60-72.

26. Hanlon JT, Landerman LR, Fillenbaum GG, et al. Falls in African American and white community-dwelling elderly residents. $J$ Gerontol A Biol Sci Med Sci 2002;57:M473-M478.

27. Faulkner KA, Cauley JA, Zmuda JM, et al. Ethnic differences in the frequency and circumstances of falling in older community-dwelling women. J Am Geriatr Soc 2005;53:1774-9.

28. Chan KM, Pang WS, Ee CH, et al. Epidemiology of falls among the elderly community dwellers in Singapore. Singapore Med $J$ 1997;38:427-31.

29. Ganz DA, Higashi T, Rubenstein LZ. Monitoring falls in cohort studies of community-dwelling older people: effect of the recall interval. $J$ Am Geriatr Soc 2005;53:2190-4.

30. Hauer K, Lamb SE, Jorstad EC, et al. Systematic review of definitions and methods of measuring falls in randomised controlled fall prevention trials. Age Ageing 2006;35:5-10.

31. Dickens J, Jones M, Johansen A. Falls definition--reliability of patients' own reports. Age Ageing 2006;35:450-1. 